\title{
The variable direct cost and cost drivers of transoral endoscopic thyroidectomy vestibular approach
}

\author{
Christopher R. Razavi, Ved A. Tanavde, Alexander S. Kim, Mohammad Shaear, Ralph P. Tufano, \\ Jonathon O. Russell \\ Department of Otolaryngology - Head \& Neck Surgery, Johns Hopkins University School of Medicine, Baltimore, MD, USA \\ Contributions: (I) Conception and design: All authors; (II) Administrative support: RP Tufano, JO Russell; (III) Provision of study materials or \\ patients: RP Tufano, JO Russell; (IV) Collection and assembly of data: CR Razavi, VA Tanavde, AS Kim; (V) Data analysis and interpretation: CR \\ Razavi, VA Tanavde, AS Kim; (VI) Manuscript writing: All authors; (VII) Final approval of manuscript: All authors. \\ Correspondence to: Jonathon O. Russell. Department of Otolaryngology - Head and Neck Surgery, The Johns Hopkins School of Medicine. Johns \\ Hopkins Outpatient Center, 601 N. Caroline Street, 6th floor, Baltimore, MD 21287, USA. Email: jrusse41@jhmi.edu.
}

Background: As transoral endoscopic thyroidectomy vestibular approach grows in popularity, there is a need for data on cost in order to better characterize its value to patients. To this end, we compared the variable direct cost of transoral endoscopic thyroidectomy vestibular approach and transcervical approach thyroidectomy and determined which factors drive the increased cost for the transoral approach.

Methods: Patients undergoing thyroid lobectomy and total thyroidectomy that met inclusion criteria for transoral endoscopic thyroidectomy vestibular approach, including those patients that opted for management via the transcervical approach, between 8/2016 and 4/2019 were reviewed. The variable direct cost for the surgical encounter was collected and means were compared between the transoral and transcervical cohorts for lobectomy and total thyroidectomy respectively. The operative time independent variable direct cost was similarly compared between cohorts.

Results: Out of 238 patients, 118 (50\%) were managed via transoral endoscopic thyroidectomy vestibular approach and 120 (50\%) were managed via transcervical approach thyroidectomy. Mean variable direct cost, our primary outcome, was $\$ 4,455$ (SD 1,129, 95\% CI: 4,204-4,706) for transoral lobectomy and \$3,179 (SD 687, 95\% CI: 2,990-3,369) for transcervical lobectomy [ $\mathrm{t}(132.05)=8.09, \mathrm{P}<0.001]$ representing a difference in cost of $\$ 1,276$ (SD 158, 95\% CI: 964-1,587). Mean variable direct cost was $\$ 4,681$ (SD 829, 95\% CI: 4,405-4,957) for transoral total thyroidectomy and \$3,645 (SD 876, 95\% CI: 3,431-3,858) for transcervical total thyroidectomy $[\mathrm{t}(79.92)=5.98, \mathrm{P}<0.001]$, representing a difference in cost of $\$ 1,036$ (SD 173, 95\% CI: 691-1,381). Differences in energy devices alone account for $\$ 487.53$ and $\$ 447.96$ of the cost differences, respectively.

Conclusions: The differences in mean variable direct cost between transoral endoscopic vestibular approach and transcervical approach for lobectomy and total thyroidectomy were \$1276 and \$1036 respectively, amounts far less than some believe them to be. This data will be invaluable as we ultimately aim to define the value of transoral endoscopic thyroidectomy vestibular approach.

Keywords: Transoral endoscopic thyroidectomy vestibular approach (TOETVA); remote-access thyroidectomy; transoral thyroidectomy; minimally-invasive thyroidectomy; endoscopic thyroidectomy; cost

Submitted Aug 17, 2020. Accepted for publication Nov 29, 2020.

doi: $10.21037 /$ gs-20-653

View this article at: http://dx.doi.org/10.21037/gs-20-653 


\section{Introduction}

The transoral endoscopic thyroidectomy vestibular approach (TOETVA) allows access to the thyroid and central neck via three incisions in the oral vestibule, facilitating thyroid surgery without a cutaneous scar (1-4). Similar to other remote-access approaches to the thyroid, TOETVA has increased in popularity as we continue to understand the negative consequences anterior cervical scars can have on patient quality of life (5-8). While these remote-access approaches have had relatively broad adoption internationally, particularly in Asia, the same cannot be said for the North American experience. The cause of this is likely multifactorial in nature (9).

Early North American experiences with remote-access techniques were marked by complications not encountered with the traditional transcervical approach (TCA) to the thyroid. These were due in part to dissection planes which were unfamiliar to most thyroid surgeons, as well as the lengthy learning curves for these procedures $(5,10-12)$. Additionally, there were concerns in regards to the cost of remote-access techniques, stemming both from increased operative times and the robotic-assisted nature of many of these approaches $(4,13,14)$. In contrast, TOETVA utilizes familiar dissection planes and has been estimated to have a significantly shorter learning curve than other remote access approaches to the thyroid $(3,4,12,15)$. Perhaps as a result, early outcomes with TOETVA have been largely free from significant adverse events, while demonstrating the feasibility of the approach (1-4,16-20). Moreover, TOETVA does not require the use of a costly robotic system, as it can be performed utilizing laparoscopic instrumentation widely available at even the smallest community hospitals.

Nevertheless, questions still remain in North America in regard to the cost of the procedure in an increasingly value-based health care system. Quantifying the increased cost of TOETVA will allow patients, health care providers, and other stakeholders to make a more informed comparison with TCA, allowing them to more precisely weigh the cosmetic benefit of TOETVA against the cost. Furthermore, understanding which factors drive the cost difference between TOETVA and TCA may highlight areas and opportunities for cost reduction. With these aims, we evaluated the cost of TOETVA in comparison to the TCA at our tertiary care academic center.

We present the following article in accordance with the MDAR checklist (available at http://dx.doi.org/10.21037/ gs-20-653).

\section{Methods}

We performed a retrospective review of patients undergoing thyroid lobectomy and total thyroidectomy that met inclusion criteria for TOETVA, including those patients that opted for management via TCA, between 8/2016 and 4/2019. As such, all patients in both cohorts met the following criteria: a thyroid lobe no larger than $10 \mathrm{~cm}$, with an index nodule no greater than $6 \mathrm{~cm}$ if the cytopathology was benign or indeterminate and no greater than $2 \mathrm{~cm}$ if it was differentiated thyroid carcinoma. Patients with evidence of substernal extension, extrathyroidal extension or nodal metastasis were excluded (21). Cases where other procedures such as central dissections, parathyroidectomy, or a Sistrunk procedure were also performed were also excluded from both the TOETVA and TCA cohorts in an effort to further maintain homogeneity of the data. For the purposes of this study, completion thyroidectomy procedures were analyzed as lobectomies for both cohorts. All cases were performed by one of two fellowship trained head and neck endocrine surgeons.

The primary outcome of our study was the mean variable direct cost (VDC) for lobectomy and total thyroidectomy by TOETVA and TCA. The VDC was defined as the sum of all hospital charges, in United States dollars, for surgical equipment, disposables, laboratory tests, medications, operating room (OR) time, anesthesia time, and preoperative and post-operative nursing in the post-anesthesia care unit (PACU) for a given case. Importantly, these charges may reflect the hospital's markup on top of the original item cost. Furthermore, this does not include the cost of labor of nursing, scrub techs, the surgeon, and any other staff in the operating room. The VDC did not include fixed costs and indirect costs as these are representative of hospital overhead and, compared to the aforementioned direct costs, are more likely to vary from institution to institution (22).

Our secondary outcome was the mean VDC after adjusting for operative time (OT) for lobectomy and total thyroidectomy by TOETVA and TCA. As OT is a factor that may vary based on progress on the surgical learning curve and the available surgical assistant, we calculated an operative time independent VDC (OIVDC), which subtracts the operating room (OR) time and $\mathrm{OR}$ anesthesia costs from the VDC. In eliminating these time-dependent costs, OIVDC allows for a like-for-like comparison between TOETVA and TCA of costs that do not vary as much with surgeon experience. This was calculated by subtracting the 
per minute cost for anesthesia and the operating room from the VDC. As our definition of VDC is based on hospital charges, without the cost of labor and hospital overhead, our analysis can be understood as an estimate of cost from the perspective of the patient.

An additional objective was to determine the major drivers of cost difference. We stratified by extent of surgery-lobectomy or total thyroidectomy-and then compared major cost drivers between TOETVA and TCA. To determine drivers of cost difference, charges were pooled for all cases of a given procedure (e.g., TCA lobectomy). We then used the net sum of all charges for a specific item and divided this by the total number of procedures performed to calculate the average cost per case of each item. Notably, this is not equivalent to the average cost of an item as certain items may have had no or multiples uses in a particular case. The variable we have termed the cost per case is therefore the average expense toward a given item. In this analysis, HARMONIC shears (Medtronic, Dublin, Ireland) and LigaSure vessel sealer/dividers (Ethicon, Cincinnati, Ohio) were grouped together as energy devices. Standard prass monopolar stimulator probes (Medtronic, Dublin, Ireland) and ball tip stimulator probes (Medtronic, Dublin, Ireland) were grouped as nerve monitoring probes. Fibrin sealant included the TISSEEL system of fibrin sealant, spray sets, or DUPLOSPRAY applicators (Baxter, Deerfield, Illinois) as well as the EVICEL fibrin sealant system (Ethicon, Cincinatti, Ohio).

\section{Statistical analysis}

Mean VDC and OIVDC were compared between the TOETVA and TCA cohorts with the unpaired Student's $t$-test assuming unequal variances (Welch's $t$-test). Mean VDC and OIVDC for lobectomies and total thyroidectomies were analyzed and compared separately. Analysis was completed in Stata Statistical Software: Release 16.1 (StataCorp LLC, College Station, Texas) using an alpha of 0.05 for statistical significance.

\section{Etbical statement}

The study was conducted in accordance with the Declaration of Helsinki (as revised in 2013). The study was approved by the Johns Hopkins Medicine Institutional Review Board (OHRP \#00000025) and individual consent for this retrospective analysis was waived.

\section{Results}

A total of 238 cases met criteria. 118 (49.6\%) patients were in the TOETVA cohort, while $120(50.4 \%)$ were in the TCA cohort. 80 of $118(68 \%)$ patients in the TOETVA cohort underwent lobectomy, while 37 (32\%) underwent total thyroidectomy. In the TCA cohort 53 of 120 (44\%) underwent lobectomy with the remaining 67 (56\%) undergoing total thyroidectomy. Almost all (117/118, 99\%) of the TOETVA cases were completed via the intended approach, with one case being converted to TCA due to superior pole bleeding that could not be controlled transorally. This case was completed without complication via TCA in 123 minutes. This case was not included in analysis of VDC/OIVDC for either the TOETVA or TCA cohorts. The median operative time was 127 minutes for TOETVA lobectomy; 176 minutes for TOETVA total thyroidectomy; 92 minutes for TCA lobectomy; and 125 minutes for TCA total thyroidectomy. The median BMI was 26.8 for TOETVA lobectomy; 30.3 for TOETVA total thyroidectomy; 28.0 for TCA lobectomy; and 30.4 for TCA total thyroidectomy. There were no cases of permanent (symptoms/deficits $>3$ months) recurrent laryngeal nerve injury in either cohort.

Our primary outcome was mean VDC. Mean VDC for TOETVA lobectomies was $\$ 4,455$ (SD 1,129, 95\% CI: 4,204-4,706), while mean VDC for TOETVA total thyroidectomies was $\$ 4,681$ (SD 829, 95\% CI: 4,405$4,957)$. For the TCA cohort, mean VDC for lobectomies and total thyroidectomies were $\$ 3,179$ (SD 687, 95\% CI: 2,990-3,369) and \$3,645 (SD 876, 95\% CI: 3,431-3,858) respectively. The difference in mean VDC between cohorts was statistically significant for both lobectomies and total thyroidectomies $[\mathrm{t}(132.05)=8.09, \mathrm{P}<0.001$ and $\mathrm{t}(79.92)=5.98$, $\mathrm{P}<.001$, respectively] (Table 1).

Our secondary outcome was mean OIVDC. Mean OIVDC for TOETVA lobectomy and total thyroidectomy were $\$ 3,370$ (SD 974, 95\% CI: 3,154-3,587) and \$3,310 (SD 833, 95\% CI: 3,032-3,588), respectively, both significantly greater than the respective mean OIVDC for TCA (\$2,409, SD 550, 95\% CI: 2,257-2,560; and $\$ 2,635$, SD 731, 95\% CI: 2,457-2,814) [t(129.90) $=7.26$, $\mathrm{P}<0.001$ and $\mathrm{t}(68.14)=4.12, \mathrm{P}<0.001$, respectively] (Table 1). The differences in means represent an additional cost of $\$ 1,275.61$ (SD 157.61, 95\% CI: 963.84-1,587.37) or $\$ 962.12$ (SD 132.54, 95\% CI: 699.91-1,224.34) by VDC and OIVDC, respectively, for TOETVA lobectomies, and an additional cost of $\$ 1036.17$ (SD 173.20, 95\% CI: 
Table 1 VDC and OIVDC by procedure

\begin{tabular}{|c|c|c|c|c|c|c|c|}
\hline \multirow[b]{3}{*}{ Procedure } & \multicolumn{6}{|c|}{ Approach } & \multirow{3}{*}{$P$ value ${ }^{\dagger}$} \\
\hline & \multicolumn{3}{|c|}{ TOETVA $(\mathrm{N}=117)$} & \multicolumn{3}{|c|}{ TCA $(\mathrm{N}=120)$} & \\
\hline & No. [\%] & $\begin{array}{l}\text { Primary outcome: } \\
\text { mean VDC }(\$)\end{array}$ & $\begin{array}{c}\text { Secondary } \\
\text { outcome: mean } \\
\text { OIVDC }(\$)\end{array}$ & No. [\%] & $\begin{array}{l}\text { Primary outcome: } \\
\text { mean VDC (\$) }\end{array}$ & $\begin{array}{l}\text { Secondary outcome: } \\
\text { mean OIVDC }(\$)\end{array}$ & \\
\hline Lobectomy & 80 [68] & $4,454.88$ & $3,370.64$ & $53[44]$ & $3,179.27$ & $2,408.52$ & $<0.001,<0.001$ \\
\hline
\end{tabular}

TOETVA, transoral endoscopic thyroidectomy vestibular approach; TCA, transcervical approach; VDC, variable direct cost; OIVDC, operative time independent variable direct cost; $\$$, United States Dollars; 'Welch's $t$-test for difference in means, TOETVA vs. TCA (VDC and OIVDC).

691.48-1,380.87) or $\$ 674.41$ (SD 163.52, 95\% CI: $348.11-$ $1,000.69)$ by VDC and OIVDC, respectively, for TOETVA total thyroidectomies (Table 1).

We previously established the point of proficiency on the surgical learning curve of TOETVA to be after 11 cases (12). In our dataset, all cases of TOETVA were performed by the same primary surgeon. As these first eleven cases were all TOETVA lobectomy, we compared the time cost-the sum of OR time and OR anesthesiology time costs-from the initial 11 cases to the time costs of all subsequent TOETVA lobectomies. The mean time cost from the first 11 cases of TOETVA lobectomy was $\$ 1,365$ (SD 307.33, 95\% CI: $1,159-1,572$ ) and $\$ 1,039$ (SD 317.84, 95\% CI: 963-1,116) from the 69 subsequent cases of TOETVA lobectomy $[\mathrm{t}(78)=3.17, \mathrm{P}=0.002]$.

In order to determine the greatest contributors to cost, as well as identify the factors responsible for the apparent fixed cost increase of TOETVA as compared to TCA, we pooled the charges for cases of the same approach (TOETVA or TCA) and extent (total thyroidectomy or lobectomy). We then ranked categories of charges by proportion of the total cost, revealing eight items which together account for approximately $80 \%$ to $83 \%$ of VDC. As costs related to OR time and OR anesthesia account for approximately $25-30 \%$ of VDC and vary with surgeon experience, we performed the same calculations using OIVDC. Having subtracted OR time cost and OR anesthesia cost, the remaining six items now accounted for approximately $74 \%$ to $77 \%$ of OIVDC. The greatest drivers of cost for TOETVA and TCA lobectomy are summarized in Table 2. The greatest drivers of cost for TOETVA and TCA total thyroidectomy are summarized in Table 3.

In identifying eight items that account for a majority of the overall cost-74 to $83 \%$, depending on procedure, approach, and cost measure-we are also able to explain a majority of the cost difference between TOETVA and TCA for lobectomy or total thyroidectomy. For lobectomy, the average VDC difference was $\$ 1,275.61$ and the average OIVDC difference was $\$ 962.13$. The eight items identified account for $75 \%$ (\$952.49) and 66\% (\$639.01) of the VDC and OIVDC cost difference, respectively (Tables 2). For total thyroidectomy, the average VDC difference was $\$ 1,036.17$ and the average OIVDC difference was $\$ 674.40$ between TOETVA and TCA. These eight items account for $91 \%$ (\$941.62) and 86\% (\$579.85) of the VDC and OIVDC cost difference, respectively (Table 3).

Nursing costs related to time spent in PACU as well as OR time and anesthesia costs account for a considerable proportion of overall cost, ranging from $41.6 \%$ to $46.6 \%$ of VDC, depending on procedure type and approach. For VDC, increased operative time for TOETVA accounts for an increase in $\$ 265.36$ and $\$ 318.74$ per case for lobectomy and total thyroidectomy, respectively (Tables 2 and 3). The cost difference between TOETVA and TCA is primarily driven by differences in instrumentation. Energy devices represented the largest driver of cost for TOETVA lobectomy or total thyroidectomy, on average increasing the cost of the case by approximately $\$ 450-500$, even higher than the approximately $\$ 300-350$ from costs related to increased operative time.

\section{Discussion}

In our TOETVA series, $99 \%$ of cases were completed via the intended approach, without incidence of permanent recurrent laryngeal nerve injury. The converted case (lobectomy) was completed without complication in 123 minutes with a VDC of $\$ 2,758.96$, less than the mean 
Table 2 Greatest contributors to cost for lobectomies

\begin{tabular}{|c|c|c|c|}
\hline Item Name & TOETVA & TCA & Cost per case difference $(\$)$ \\
\hline OR time cost & 910.10 & 644.74 & 265.36 \\
\hline OR anesthesiology time cost & 174.13 & 126.01 & 48.12 \\
\hline PACU pre-op charge & 95.82 & 98.49 & -2.67 \\
\hline Energy devices & $1,014.17$ & 526.64 & 487.53 \\
\hline Endotracheal tube & 474.67 & 479.28 & -4.61 \\
\hline Nerve monitoring probe & 194.41 & 128.76 & 65.65 \\
\hline Fibrin sealant & 224.39 & 179.10 & 45.29 \\
\hline VDC (primary outcome) & $4,454.88$ & $3,179.27$ & $1,275.61$ \\
\hline OIVDC (secondary outcome) & $3,370.64$ & $2,408.52$ & 962.12 \\
\hline
\end{tabular}

OR, operating room; PACU, post-anesthesia care unit; OI item total, operative time independent item total; VDC, variable direct cost; OIVDC, operative time independent variable direct cost; \$, United States Dollars.

Table 3 Greatest contributors to cost for total thyroidectomies

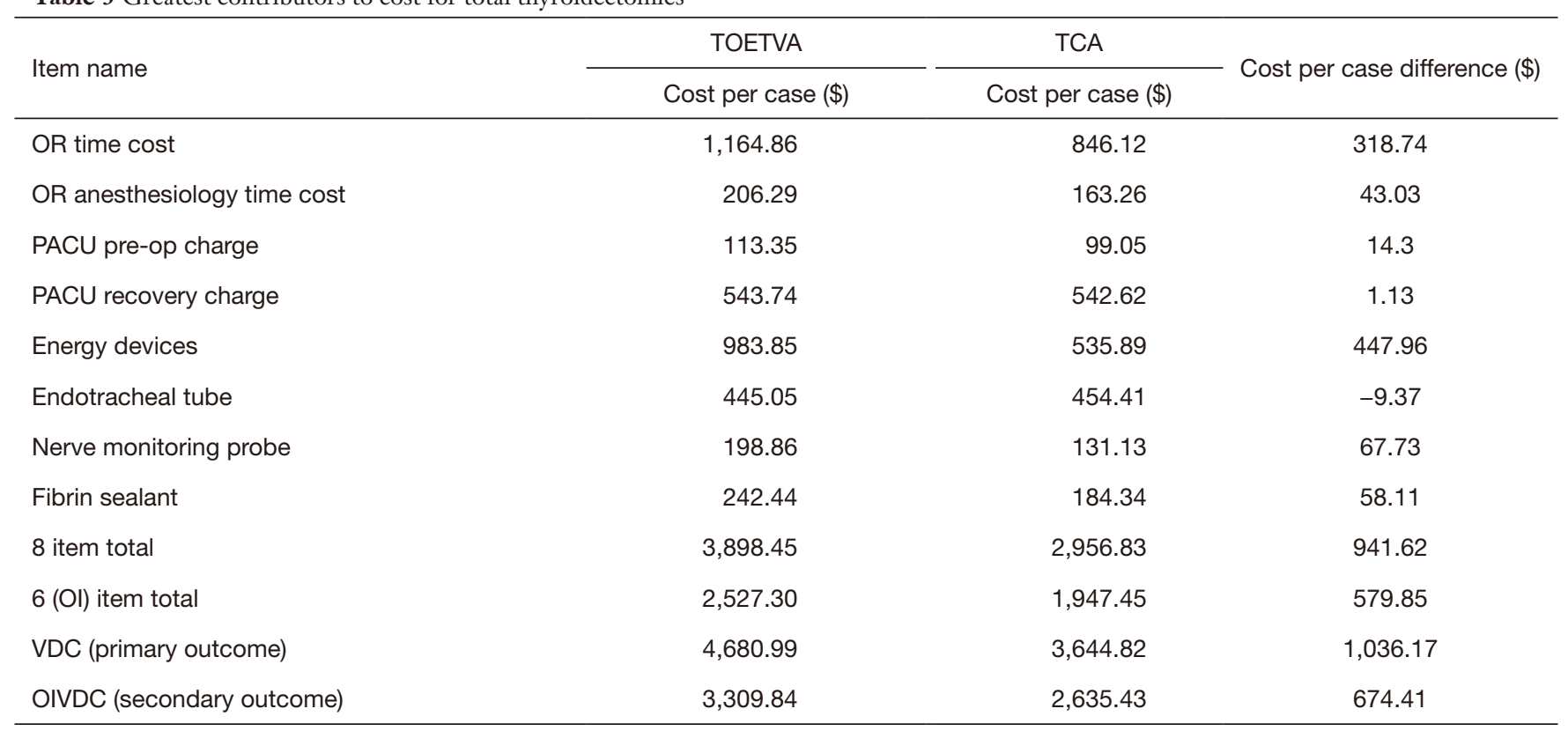

OR, operating room; PACU, post-anesthesia care unit; OI item total, operative time independent item total; VDC, variable direct cost; OIVDC, operative time independent variable direct cost; \$, United States Dollars.

VDC for the TOETVA lobectomy series. As there was no incidence of recurrent laryngeal nerve injury in the TOETVA cohort, no patient in this series incurred an additional cost from a related future procedure. Hence the VDC for the TOETVA cohort can be considered an appropriate surrogate for the cost of the procedure. 
Though this same data on nerve injury was not specifically available for review for the TCA cohort, when considering the historical rate of permanent recurrent laryngeal nerve injury (as a result of unintentional iatrogenic injury) of $0.2 \%$ at our institution, we would not expect this to significantly impact the cost of the TCA cohort (23). Therefore, we can likewise consider VDC to be an appropriate surrogate for cost in the TCA cohort.

We have shown the VDC of TOETVA lobectomy is approximately $\$ 1,280$ greater than that of TCA lobectomy. Similarly, the VDC of TOETVA total thyroidectomy is approximately $\$ 1,040$ greater than that of TCA total thyroidectomy. The eight factors we have described above account for a majority ( $75 \%$ to $91 \%$ ) though not the totality of the cost difference. Multiple small expenses for unique items or minor differences in cost for common items, in the aggregate, account for the remainder of the cost difference.

Our results suggest the cost difference is largely driven by differences in instrumentation. The ball tip stimulator probe (Medtronic, Dublin, Ireland) and energy devices like HARMONIC shears (Ethicon, Cincinnati, Ohio) and the LigaSure Maryland jaw device (Medtronic, Dublin, Ireland) are typically used in TOETVA cases, whereas the standard prass monopolar stimulator probe (Medtronic, Dublin, Ireland) and LigaSure thoracic sealer/divider (Medtronic, Dublin, Ireland) are typically used in TCA cases. These instruments can be considered to be relatively unique to each technique, whereas tracheal tubes and fibrin sealants are common to both and, although slightly discrepant in cost between procedure type, are not large drivers of the overall difference in cost. Our data shows differences in energy devices for TOETVA lobectomy or total thyroidectomy add an average of $\$ 487.53$ or $\$ 447.96$ per case, respectively. Our finding that the OIVDC of TOETVA is slightly higher for lobectomy $(\$ 3,370.64)$ than total thyroidectomy $(\$ 3309.84)$ is unexpected but can be explained by the presence of outliers. In six TOETVA lobectomies, one or two additional HARMONIC shears (Ethicon, Cincinnati, Ohio) were utilized, usually due to contamination of an instrument, with each case representing an outlier in terms of overall cost. Overall, instrument cost is higher for TOETVA and, along with increased OR time cost, largely explains the increased cost when compared to TCA.

Notably, the increase in cost of TOETVA is $28 \%$ $(\$ 1,036.17)$ to $40 \%(\$ 1,275.61)$ for total thyroidectomy and lobectomy, respectively. This is considerably lower than Broome et al.'s finding of a $117 \%$ cost increase $(\$ 3,127)$ for robotic thyroidectomy as compared to standard open thyroidectomy (24). In their study, operative times were drawn from high-volume, robotic-experienced surgeons, leading to operative times comparable to those of the open thyroidectomy cases. Additionally, the cost of the robotic system with yearly depreciation was included. TOETVA thyroid surgery would obviate the need for disposables specific to the robotic system as well as the large upfront expense of the robotic system.

Though we have determined there to be a difference in cost between TOETVA and TCA in our early experience, we have yet to fully determine the potential value the procedure may have. To do so we must better understand the societal penalty the presence of an anterior cervical neck scar may cause, as well as what the willingness to pay of a casual observer to avoid this consequence may be. If the willingness to pay value is greater than the difference in cost between TOETVA and TCA, TOETVA can be considered to provide substantial value to patients and society. While this paper does attempt to define the costs associated with avoiding a scar during thyroid surgery, the authors are unable to make actionable suggestions at this time. The impact of a cervical incision may vary by society. Future studies are needed to determine this.

Our study has a few important limitations. The first is our data is based on hospital charges from a single institution in the United States. Given marked differences in hospital charges and the costs of medical instruments, our conclusions are unlikely to be generalizable to other countries. Additionally, our variable estimating cost, VDC, is based on hospital charges, which may reflect a price markup from the original cost of an item. One assumption of our analysis is that the degree of markup is consistent between the two surgical approaches, which is reflected in the similar cost per case of items common to both procedures, such as the endotracheal tube. Finally, we did not have data on the cost of labor, which may vary tremendously from institution to institution. Even so, this is likely a substantial expense which may alter conclusions regarding the cost penalty of TOETVA and therefore its value.

\section{Conclusions}

Based on data from a single institution in the United States, TOETVA costs significantly more (about $\$ 1,100$ per case) than TCA for both lobectomy and total thyroidectomy, with this difference in cost principally driven by differences in instrumentation and variable instrument cost. Further studies aimed at identifying the societal penalty for anterior 
neck scarring in conjunction with the societal WTP to avoid this complication will be crucial in determining the ultimate value of TOETVA.

\section{Acknowledgments}

We thank John Hundt for providing data related to surgical equipment, anesthesia, and other expenses.

Funding: None.

\section{Footnote}

Reporting Checklist: The authors have completed the MDAR checklist. Available at http://dx.doi.org/10.21037/gs-20-653

Data Sharing Statement: Available at http://dx.doi. org/10.21037/gs-20-653

Conflicts of Interest: All authors have completed the ICMJE uniform disclosure form (available at http://dx.doi. org/10.21037/gs-20-653). Ralph P. Tufano, MD, MBA, is a consultant for Medtronic and Hemostatix and serves as an Editorial Board Member of Gland Surgery from September 2020 to August 2022. Jonathon O. Russell, MD, is a consultant for Baxter Scientific. The JOR authors have no conflicts of interest to declare.

Ethical Statement: The authors are accountable for all aspects of the work in ensuring that questions related to the accuracy or integrity of any part of the work are appropriately investigated and resolved. The study was conducted in accordance with the Declaration of Helsinki (as revised in 2013). The study was approved by the Johns Hopkins Medicine Institutional Review Board (OHRP \#00000025) and individual consent for this retrospective analysis was waived.

Open Access Statement: This is an Open Access article distributed in accordance with the Creative Commons Attribution-NonCommercial-NoDerivs 4.0 International License (CC BY-NC-ND 4.0), which permits the noncommercial replication and distribution of the article with the strict proviso that no changes or edits are made and the original work is properly cited (including links to both the formal publication through the relevant DOI and the license). See: https://creativecommons.org/licenses/by-nc-nd/4.0/.

\section{References}

1. Anuwong A. Transoral Endoscopic Thyroidectomy Vestibular Approach: A Series of the First 60 Human Cases. World J Surg 2016;40:491-7.

2. Russell JO, Clark J, Noureldine SI, et al. Transoral thyroidectomy and parathyroidectomy - A North American series of robotic and endoscopic transoral approaches to the central neck. Oral Oncol 2017;71:75-80.

3. Anuwong A, Ketwong K, Jitpratoom P, et al. Safety and Outcomes of the Transoral Endoscopic Thyroidectomy Vestibular Approach. JAMA Surg 2018;153:21-7.

4. Razavi CR, Khadem MGA, Fondong A, et al. Early outcomes in transoral vestibular thyroidectomy: Robotic versus endoscopic techniques. Head Neck 2018;40:2246-53.

5. Berber E, Bernet V, Fahey TJ 3rd, et al. American Thyroid Association Statement on Remote-Access Thyroid Surgery. Thyroid 2016;26:331-7.

6. Arora A, Swords C, Garas G, et al. The perception of scar cosmesis following thyroid and parathyroid surgery: A prospective cohort study. Int J Surg 2016;25:38-43.

7. Best AR, Shipchandler TZ, Cordes SR. Midcervical scar satisfaction in thyroidectomy patients. Laryngoscope 2017; 127:1247-52.

8. Juarez MC, Ishii L, Nellis JC, et al. Objectively measuring social attention of thyroid neck scars and transoral surgery using eye tracking. Laryngoscope 2019;129:2789-94.

9. Russell JO, Anuwong A, Dionigi G, et al. Transoral Thyroid and Parathyroid Surgery Vestibular Approach: A Framework for Assessment and Safe Exploration. Thyroid 2018;28:825-9.

10. Kim WW, Jung JH, Park HY. The Learning Curve for Robotic Thyroidectomy Using a Bilateral Axillo-Breast Approach From the 100 Cases. Surg Laparosc Endosc Percutan Tech 2015;25:412-6.

11. Lee J, Yun JH, Nam KH, et al. The learning curve for robotic thyroidectomy: a multicenter study. Ann Surg Oncol 2011;18:226-32.

12. Razavi CR, Vasiliou E, Tufano RP, et al. Learning Curve for Transoral Endoscopic Thyroid Lobectomy. Otolaryngol Head Neck Surg 2018;159:625-9.

13. Kandil E, Hammad AY, Walvekar RR, et al. Robotic Thyroidectomy Versus Nonrobotic Approaches: A MetaAnalysis Examining Surgical Outcomes. Surg Innov 2016;23:317-25. 
14. Russell JO, Razavi CR, $\mathrm{Al}$ Khadem MG, et al. Anterior cervical incision-sparing thyroidectomy: Comparing retroauricular and transoral approaches. Laryngoscope Investig Otolaryngol 2018;3:409-14.

15. Razavi CR, Fondong A, Tufano RP, et al. Central neck dissection via the transoral approach. Ann Thyroid 2017;2:11.

16. Dionigi G, Bacuzzi A, Lavazza M, et al. Transoral endoscopic thyroidectomy: preliminary experience in Italy. Updates Surg 2017;69:225-34.

17. Jitpratoom P, Ketwong K, Sasanakietkul T, et al. Transoral endoscopic thyroidectomy vestibular approach (TOETVA) for Graves' disease: a comparison of surgical results with open thyroidectomy. Gland Surg 2016;5:546-52.

18. Razavi CR, Tufano RP, Russell JO. Completion thyroidectomy via the transoral endoscopic vestibular approach. Gland Surg 2018;7:S77-S79.

19. Russell JO, Razavi CR, Garstka ME, et al. Remote-Access Thyroidectomy: A Multi-Institutional North American

Cite this article as: Razavi CR, Tanavde VA, Kim AS, Shaear M, Tufano RP, The variable direct cost and cost drivers of transoral endoscopic thyroidectomy vestibular approach. Gland Surg 2021;10(2):521-528. doi: 10.21037/gs-20-653
Experience with Transaxillary, Robotic Facelift, and Transoral Endoscopic Vestibular Approaches. J Am Coll Surg 2019;228:516-22.

20. Russell JO, Razavi CR, Shaear M, et al. Transoral Vestibular Thyroidectomy: Current State of Affairs and Considerations for the Future. J Clin Endocrinol Metab 2019;104:3779-84.

21. Razavi CR, Russell JO. Indications and contraindications to transoral thyroidectomy. Ann Thyroid 2017;2:12.

22. Taheri PA, Butz D, Griffes LC, et al. Physician impact on the total cost of care. Ann Surg 2000;231:432-5.

23. Dhillon VK, Rettig E, Noureldine SI, et al. The incidence of vocal fold motion impairment after primary thyroid and parathyroid surgery for a single high-volume academic surgeon determined by pre- and immediate post-operative fiberoptic laryngoscopy. Int J Surg 2018;56:73-8.

24. Broome JT, Pomeroy S, Solorzano CC. Expense of robotic thyroidectomy: a cost analysis at a single institution. Arch Surg 2012;147:1102-6. 